\title{
Clinical response to interferon beta and glatiramer acetate in multiple sclerosis patients: a Brazilian cohort
}

\author{
Resposta terapêutica ao interferon beta e ao acetato de glatiramer em pacientes com \\ esclerose múltipla: estudo de uma coorte brasileira \\ Valéria Coelho Santa Rita Pereira³, Fabíola Rachid Malfetano ${ }^{3,4}$, Isabella D’Andrea Meira³, Letícia Fêzer de \\ Souza ${ }^{3}$, Assuncion Martinez Liem³ ${ }^{3}$ Angelo Maiolino ${ }^{5}$, Soniza Vieira Alves Leon ${ }^{1,2,3}$
}

\begin{abstract}
Introduction: Many patients with multiple sclerosis (MS) are currently receiving treatment with interferon beta (IFNb) and glatiramer acetate (GA). Identifying nonresponders patients is important to define therapy strategies. Several criteria for treatment response to IFNb and GA have been proposed. Objective: It was to investigate the response to treatment with IFNb-1a, IFNb-1b and GA among relapsing-remitting multiple sclerosis (RRMS) patients. Methods: We analyzed treatment response to IFNb and GA in ninety-one RRMS patients followed for at least one year. Clinical response was established by clinical criteria based on relapses, disability progression or both. Results: We observed a proportion of nonresponders, ranging from 3.3 to 42.9\%, depending on the stringency of the criteria used. Conclusions: Our sample of Brazilian patients with MS has similarities when compared to other studies and there was no statistically significant difference regarding age, gender, ethnicity or disease duration between responders and nonresponders.
\end{abstract}

Key words: multiple sclerosis, interferon-beta, glatiramer acetate, therapeutics.

\section{RESUMO}

Introdução: Muitos pacientes com esclerose múltipla (EM) estão atualmente recebendo tratamento com interferon beta (IFNb) e acetato de glatiramer (AG). Identificar pacientes não respondedores é importante para definir estratégias terapêuticas. Foram propostos vários critérios para definir a resposta ao tratamento com IFNb e AG. Objetivo: Foi investigar a resposta ao tratamento com IFNb-1a, IFNb-1b e AG entre pacientes com esclerose múltipla remitente-recorrente (EMRR). Métodos: Analisamos a resposta ao tratamento com IFNb e AG em 91 pacientes com EMRR acompanhados por um período de pelo menos um ano. A resposta clínica foi estabelecida por critérios baseados em surtos, progressão da incapacidade ou ambos. Resultados: Observamos uma proporção de não respondedores que variou de 3,3 a 42,9\%, dependendo do rigor do critério utilizado. Conclusões: Nossa amostra de pacientes brasileiros com EM tem semelhanças quando comparada a outros estudos e não apresentou diferença estatisticamente significativa entre respondedores e não respondedores com relação à idade, sexo, etnia ou duração da doença.

Palavras-Chave: esclerose múltipla, interferon beta, acetato de glatiramer, terapêutica.

Multiple sclerosis (MS) is an inflammatory demyelinating and neurodegenerative disease of the central nervous system (CNS) resulting from aberrant immune response to self-antigens that lead to destruction of myelin ${ }^{1}$, where both the adaptive and innate immunity play an important role in the initiation and maintenance of the disease ${ }^{2}$. MS has a highly heterogeneous clinical course with different immunogenetic features, neuroradiological and therapeutic response often ethnicity-dependent ${ }^{3,4}$. MS has been considered a model of individualized medicine ${ }^{5}$. In recent decades, the treatment of MS has included modifying treatments of its clinical course, with so-called modifying agents of the disease course (MADC). The knowledge of the stages and mechanisms associated with MS enables the development

\footnotetext{
${ }^{1}$ Neurologist Associate Professor, Universidade Federal do Estado do Rio de Janeiro (UNIRIO), Rio de Janeiro RJ, Brazil;

${ }^{2}$ Neurology Postgraduation Program UNIRIO, Rio de Janeiro RJ, Brazil;

${ }^{3}$ Hospital Universitário Clementino Fraga Filho, Universidade Federal do Rio de Janeiro (UFRJ), Rio de Janeiro RJ, Brazil;

${ }^{4}$ Neurologist, Hospital Naval Marcílio Dias, Rio de Janeiro RJ, Brazil.

${ }^{5}$ Department of Internal Medicine, UFRJ, Rio de Janeiro RJ, Brazil.

Correspondence: Soniza Vieira Alves Leon; Serviço de Neurologia, Hospital Universitário Clementino Fraga Filho, UFRJ, Cidade Universitária; Rua Professor Rodolpho Paulo Rocco 255; 21941-617 Rio de Janeiro RJ - Brasil; E-mail: sonizavleon@globo.com

Conflict of interest: There is no conflict of interest to declare.

Received 27 July 2011; Received in final form 12 June 2012; Accepted 19 June 2012
} 
of molecules for therapeutic purposes that target some of these mechanisms. Among these drugs, are immunomodulators, interferons beta (IFN) and glatiramer acetate (GA) $)^{6,7 .}$ Immunomodulators, interferon beta- $1 \mathrm{a}$ and $-1 \mathrm{~b}$ (IFNb-1a and $-1 b$ ) and GA reduce the frequency and severity of relapses, thus altering the progression of the disease, when in relapsing-remitting form. They are available in Brazil GA 20 mg subcutaneos (sc) daily, IFNb-1a $30 \mu \mathrm{g}$, intramuscularly once a week, INF- $\beta$-la $22 \mu \mathrm{g}$ subcutaneous three times a week, INF- $\beta$-1a $44 \mu \mathrm{g}$ sc three times a week and INF- $\beta$-1b $250 \mu \mathrm{g}$ sc every other day. These drugs have been supplied by the Government, as required by Federal Law 8080, dated 19.09.1990, which provides for the Unified Health System, especially the section VI, Article 6, which regulates the right of access to medicines for health care.

Therapeutic response of immunomodulators in an ethnically heterogeneous population such as Brazilians should be analyzed, considering that clinical trials in European, Americans and Canadian patients included mainly Caucasians MS patients. Cree et al. observed that 36 Africandescent compared with 616 white Caucasians with MS had a poorer response to interferon ${ }^{4}$. In Brazil, a third of patients with MS are African-descent ${ }^{1,3}$.

In this context, monitoring of therapeutic responses to immunomodulators is critical for the patient, who now lives in an era of therapeutic strategies and resources that have been available for less than two decades. The knowledge of the biological aspects of MS allows us to establish therapeutic windows of nonresponders to early intervention ${ }^{8}$. Finding nonresponders within the population in treatment is an ongoing challenge that requires the Expanded Disability Status Scale (EDSS) score at each visit, the monitoring of new lesions on MRI each year and the number of relapses in each period. The goal of this study was to investigate the frequency of responders and nonresponders in a cohort of Brazilian MS patients in the city of Rio de Janeiro and analyze the correlation between clinical variables, disease duration and EDSS associated with response and non-response to treatment.

\section{METHOD}

Of the cohort of 236 MS patients followed prospectively at the University Hospital Clementino Fraga Filho, Universidade Federal do Rio de Janeiro (HUCFF/UFRJ), 67 were excluded because they did not use immunomodulatory (Primary Progressive Multiple Sclerosis [PPMS] and Secondary Progressive Multiple Sclerosis [SPMS]). Another 23 were excluded due to failure to follow the treatment or have they begun the first immunomodulator at another hospital. Included in this analysis were 146 patients with RRMS according to criteria of McDonald et al., 2010'. The criteria
Table 1. Different definitions of non-response based on measures of disability increase and/or relapse rate after one year of follow-up in patients treated with interferon beta and GA (adapted from Río et al. ${ }^{10}$ )

\section{Nonresponder definitions}

A An increase of at least one EDSS step confirmed at one year

B Presence of any relapse confirmed at one year

C Presence of two or more relapses confirmed at one year

D A decrease in relapse rate less than $50 \%$ compared with one year before therapy

E No decrease or higher relapse rate compared with one year before therapy

F Definition A or B

G Definition A + B

EDSS: Expanded Disability Status Scale; GA: glatiramer acetate.

for response and non-response were applied as defined by Río et al. ${ }^{10}$ that consider relapsing and increased EDSS alone or in combination (Table 1).

Of the 146 patients, 91 made regular treatment using the first immunomodulator drug by at least one year. Sixty-nine patients $(29.24 \%)$ were treated with IFNb and 22 patients $(9.32 \%)$ with glatiramer acetate. In the analysis of the results, there was no stratification by immunomodulators, based on the fact that clinical trials showed no significant difference in therapeutic response between them ${ }^{11}$. Patients were evaluated regularly every three months, and relapses, whenever occurred. Relapses and progression were measured by the functional system scale (FS) and the Expanded Disability Status Scale recorded by two neurologists independent evaluators. To define the relapsing, it was used the Poser et al. criteria - the appearance of one or more symptoms of neurological dysfunction that lasted more than 24 hours - objectively confirmed by neurological examination ${ }^{12}$. Analysis of demographic and clinical characteristics included sex, ethnicity, age, age at onset, disease duration, the number of relapses and EDSS score was confirmed every six months of the study ${ }^{13}$. Patients whose available data did not allow the analysis of the proposed variables or those who missed the deadlines were excluded. They were defined as non-response to treatment when after at least one year of treatment disease activity peaked measured by relapses and/or there was gradual progression of disability measured by EDSS $^{10,14}$ ${ }^{20}$. Clinical data was entered into a database and analyzed with the statistical analysis software SPSS, version 17.0 for Windows (SPSS, Chicago, IL). Differences in demographic details (age, sex and level of education) between responders and nonresponders patients were compared using the $\chi^{2}$ test. Mean scores of the various data from MS patients were compared to demographic characteristics using Student's $t$ test. The impact of immunomodulatory drugs performance was analyzed using a multivariate logistic regression analysis of factors influencing clinical response to treatment with IFNb and were included in the model as independent variables - sex, ethnicity, age at onset, the duration of the 
disease and the score EDSS at baseline - and as dependent variables - the state of responder or nonresponder to treatment. Analysis also considered Kaplan-Meier probability of remaining free of relapse and an increased progression of disability of one EDSS point or more. Student's $t$-test and One way Analysis of Variance (ANOVA) was appropriate and generated p-value. $\mathrm{P}<0.05$ was taken as being significant. This study was approval by the Ethical Committee of University Hospital Clementino Fraga Filho.

\section{RESULTS}

The percentage of female patients was $74.7 \%(n=68)$, and $25.3 \%(n=23)$ were male. Seventy-one patients were Caucasians and twenty non-Caucasians. The mean age at onset was 30 years (range 5-51). The mean age when starting the drug was 35 years (range 13-65). The average number of relapses in the years before the start of treatment was 1.51 (range 0-6). The median EDSS at the beginning of the immunomodulator was 2.6 (range 0-6.5).

According to Río et al. ${ }^{10}$, the different criteria used as non-response were distributed according to the following groups, which rely on the presence of relapses, increase of disability, or both, one year after each patient started treatment (Table 1). The proportion of responders and nonresponders differed greatly depending on the response definition adopted (Table 2 and 3). When the increasing disability was considered, the frequency of nonresponders was $3.3 \%$, and when it was adopted the criteria for relapse and progression of disability, non-response to this frequency was $42.9 \%$. Considering as non-response the increased EDSS of at least

Table 2. Responder and nonresponder status for the different definitions (adapted from Río et al. ${ }^{10}$ )

\begin{tabular}{|c|c|c|c|c|c|}
\hline \multirow{3}{*}{$\begin{array}{l}\text { Group all } \\
\text { patients }\end{array}$} & \multicolumn{5}{|c|}{ Responder and nonresponder status for the different definitions } \\
\hline & \multirow{2}{*}{ Nonresponder definitions } & \multicolumn{4}{|c|}{ \% patients $(\mathrm{n})$} \\
\hline & & R/NR & IFNb +AG $(n=91)$ & IFNb $(n=69)$ & $\mathrm{GA}(n=22)$ \\
\hline \multirow[t]{2}{*}{ A } & \multirow{2}{*}{$\begin{array}{l}\text { An increase of at least one EDSS step confirmed } \\
\text { at one year }\end{array}$} & R & $96.7(88)$ & $97.1(67)$ & $95.5(21)$ \\
\hline & & NR & $3.3(3)$ & $2.9(2)$ & $4.5(1)$ \\
\hline \multirow[t]{2}{*}{ B } & \multirow[t]{2}{*}{ Presence of any relapse confirmed at one year } & $\mathrm{R}$ & $57.1(52)$ & $56.5(39)$ & $59.1(13)$ \\
\hline & & NR & $42.9(39)$ & $43.5(30)$ & $40.9(9)$ \\
\hline \multirow[t]{2}{*}{ C } & \multirow{2}{*}{$\begin{array}{l}\text { Presence of two or more relapses confirmed at } \\
\text { one year }\end{array}$} & $\mathrm{R}$ & $86.8(79)$ & $87.0(60)$ & $86.4(19)$ \\
\hline & & $N R$ & $13.2(12)$ & $13.0(9)$ & $13.6(3)$ \\
\hline \multirow[t]{2}{*}{ D } & \multirow{2}{*}{$\begin{array}{l}\text { A decrease in relapse rate less than } 50 \% \\
\text { compared with one year before therapy }\end{array}$} & $\mathrm{R}$ & $62.6(57)$ & $63.8(44)$ & $59.1(13)$ \\
\hline & & NR & $37.4(34)$ & $36.2(25)$ & $40.9(9)$ \\
\hline \multirow[t]{2}{*}{$E$} & \multirow{2}{*}{$\begin{array}{l}\text { No decrease or higher relapse rate compared } \\
\text { with one year before therapy }\end{array}$} & $\mathrm{R}$ & $76.9(70)$ & $78.3(54)$ & $72.7(16)$ \\
\hline & & $N R$ & $23.1(21)$ & $21.7(15)$ & $27.3(6)$ \\
\hline \multirow[t]{2}{*}{$F$} & \multirow[t]{2}{*}{ A or $B$} & $\mathrm{R}$ & $57.1(52)$ & $56.5(39)$ & $59.1(13)$ \\
\hline & & NR & $42.9(39)$ & $43.5(30)$ & $40.9(9)$ \\
\hline \multirow[t]{2}{*}{ G } & \multirow[t]{2}{*}{$A+B$} & $\mathrm{R}$ & 96.7 (88) & $97.1(67)$ & $95.5(21)$ \\
\hline & & NR & $3.3(3)$ & $2.9(2)$ & $4.5(1)$ \\
\hline
\end{tabular}

R: Responder; NR: Nonresponder; EDSS: Expanded Disability Status Scale; INFb: interferon beta; GA: glatiramer acetate.

Table 3. Demographics and baseline clinical characteristics of patients according to the responder status to IFNb and GA for the different definitions, mean standard deviation (adapted from Rio et al. ${ }^{10}$ ).

\begin{tabular}{|c|c|c|c|c|c|c|c|}
\hline GROUP & $R \times N R$ & PATIENTS (\%) & $\mathrm{AGE}^{\mathrm{a}}(\mathrm{yr})$ & SEX \% FEM & $\begin{array}{c}\text { MS DURATION } \\
\text { BASELINE (MONTH) }\end{array}$ & RELAPSES ${ }^{b}$ & $\begin{array}{c}\text { EDSS } \\
\text { BASELINE }\end{array}$ \\
\hline \multirow[t]{2}{*}{ A } & $\mathrm{R}$ & 96.7 & $30.6(9.7)$ & 74 & $64.6(67.7)$ & $1.5(1.0)$ & $2.6(2.2)$ \\
\hline & NR & 3.3 & $19.3(10.2)$ & 100 & $31.2(24.7)$ & $2(1.0)$ & $4.0(1.8)$ \\
\hline \multirow[t]{2}{*}{ B } & $\mathrm{R}$ & 57.1 & $31.6(9.8)$ & 73 & 59.7 (67.9) & $1.3(0.9)$ & $2.6(2.2)$ \\
\hline & NR & 42.9 & $28.4(9.6)$ & 77 & $68.5(66.2)$ & $1.7(1.1)$ & $2.7(2.3)$ \\
\hline \multirow[t]{2}{*}{ C } & $\mathrm{R}$ & 86.8 & $31.1(9.7)$ & 74 & $61.0(64.9)$ & $1.4(0.9)$ & $2.7(2.3)$ \\
\hline & NR & 13.2 & $25.1(9.8)$ & 82 & $79.7(80.6)$ & $2.3(1.6)$ & $2.6(2.0)$ \\
\hline \multirow[t]{2}{*}{ D } & $\mathrm{R}$ & 62.6 & $29.4(9.9)$ & 77 & $57.6(60.2)$ & $1.8(0.9)$ & $2.4(2.1)$ \\
\hline & NR & 37.4 & $31.7(9.6)$ & 71 & $73.3(76.9)$ & $0.9(1.0)$ & $3.0(2.4)$ \\
\hline \multirow[t]{2}{*}{$E$} & $\mathrm{R}$ & 76.9 & $29.9(10.1)$ & 77 & $64.4(68.5)$ & $1.6(1.1)$ & $2.6(2.2)$ \\
\hline & NR & 23.1 & $31.4(9.1)$ & 67 & $60.3(62.8)$ & $1.0(0.6)$ & $2.8(2.3)$ \\
\hline \multirow[t]{2}{*}{$\mathrm{F}$} & $\mathrm{R}$ & 57.1 & $31.6(9.8)$ & 73 & $59.7(67.9)$ & $1.3(0.9)$ & $2.6(2.2)$ \\
\hline & NR & 42.9 & $28.4(9.6)$ & 77 & $68.5(66.2)$ & $1.7(1.1)$ & $2.7(2.3)$ \\
\hline \multirow[t]{2}{*}{ G } & $\mathrm{R}$ & 96.7 & $30.6(9.7)$ & 74 & $64.6(67.7)$ & $1.5(1.0)$ & $2.6(2.2)$ \\
\hline & $N R$ & 3.3 & $19.3(10.2)$ & 100 & $31.2(24.7)$ & $2.0(1.0)$ & $4.0(1.8)$ \\
\hline
\end{tabular}

R: Responders; NR: nonresponders; IFNb: interferon beta; GA: glatiramer acetate. ${ }^{a}$ age on the first symptom; ${ }^{b}$ relapses in the one year before INFb and GA therapy. No significant differences between responders and nonresponders were found ( $p>0.05)$. 
one point in the first year of treatment, 3.3\% were nonresponders against $96.7 \%$ of respondents. Giving attention to the presence of a new relapse during the first year of treatment, $42.9 \%$ were nonresponders versus $57.1 \%$ of responders. Not withstanding, if it was considered the presence of two or more new relapses in the course of a year, the frequency of nonresponders fell to $13.2 \%(n=12)$. Also, in relation to new relapses, taking in consideration the reduction in relapse rate greater than or equal to $50 \%$ when compared to last year, it was found $37.4 \%$ of nonresponders $(n=34)$; when there was no reduction or increase in relapse rate compared to the previous year, $23.1 \%(n=21)$ were nonresponders.

The period of disease before starting immunomodulatory treatment (Table 4) ranged from 2.2 to 336.9 months (mean 59.7 months) among responders patients and 1.2 and 256.6 months (mean 68.5 months) among nonresponders $(\mathrm{p}=0.381)$. The average duration of disease when starting the drug was different among the immunomodulators drugs (Table 5). The smallest time interval of 26.6 was observed with IFNb-1a - $44 \mathrm{mg}$ that presented a percentage of $71 \%$ of responding patients. The longest interval was 98.8 months for IFNb-1b which showed a percentage of $50 \%$ of responders patients. Among other immunomodulators, the average was $48.4 \mathrm{~m}$ for the GA (59\% of responders), $50.7 \mathrm{~m}$ for the IFNb$1 \mathrm{a}-30 \mathrm{mg}$ ( $50 \%$ of responders) and $53.0 \mathrm{~m}$ for the IFNb-1a - $22 \mathrm{mg}$ (80\% of responders).

The number of relapses before starting the first immunomodulator ranged from 1 to 29 among nonresponders patients (mean 5.6) and 1 to 10 (average 3.2) for patients who responded to treatment. The number of relapses in the first year of treatment for nonresponders patients ranged from 1 to 6 (average 1.5). Twenty-eight patients $(71.8 \%)$ had only one relapse in the first year of treatment and seven (17.9\%), two relapses. In twenty-four patients $(61.5 \%)$, the relapse had not committed new functional system (EDSS scale).

Considering the presence of any relapse or increase in the EDSS (F), $60.9 \%$ of males and $55.9 \%$ of females were considered responders $(\mathrm{p}=0.466)$. Regarding ethnicity, $56.3 \%$ of Caucasians patients and $60 \%$ of non-Caucasians were nonresponders. There was no statistically significant difference regarding age, gender, ethnicity or disease duration between responders and nonresponders. The percentage of responders to IFNb was $56.5 \%(n=39 / 69)$ and to GA, $59.1 \%(n=13 / 22)$.

\section{DISCUSSION}

The knowledge of the biology of multiple sclerosis and the proper diagnosis of different forms of evolution are fundamental in deciding treatment ${ }^{21}$. The challenge for neurologists is to choose the best therapeutic strategy among the current arsenal of drugs absent for less than two decades. Identifying the right time to start and maintaining or changing the proposed treatment should be part of this strategy. In relation to treatment with INF $\beta$ and GA, a clear definition of the lack of response in RRMS and no clinical response can be considered according to the relapse rate, disability progression or both. The studies contribute to the analysis of response and subsequent treatment decisions. MS patients have been followed up and monitored according to the number of relapses before and after drug administration, means of scales of disability (EDSS), and lesion load has been measured with MRI sequence.

The present study showed a prevalence of female and almost one third of them were non-Caucasians, a percentual that is characteristic of MS gender and ethnic distribution in the southeast region of Brazil' ${ }^{1}$.

Considering only IFNb treatment, the present study showed a proportion of patients ranging from nonresponders according to established criteria suggested in different studies $^{4,10,22,23}$. Here, we found a frequency of $2.9 \%$ of nonresponders patients when considered the increase of disability by EDSS during the first year of treatment, that is lower than the results of Río et al. ${ }^{10}$, which found $18 \%$ of patients. We can not compare our results with Cree et al. ${ }^{22}$ because the authors did not analyze disability progression among the 36 AfricanAmerican and 616 Caucasian patients studied. Regarding the presence of at least one relapse during the first year of treatment, we found $43.5 \%$ of nonresponders, and Río et al. ${ }^{10}$ found $45 \%$. However, when we consider two or more relapses as nonresponder criteria, this percentage decreases to $13.0 \%$. Río et al. ${ }^{10}$ also found a decrease in this number when considered two or more relapses (20\% of nonresponders).

Table 4. Demographics and baseline clinical characteristics of patients (IFNb and GA, Group F).

\begin{tabular}{|c|c|c|c|c|c|c|}
\hline & \multicolumn{2}{|c|}{$\operatorname{Sex} p=0.466^{*}$} & \multicolumn{2}{|c|}{ Ethnicity $p=0.615^{*}$} & \multirow{2}{*}{$\begin{array}{l}\text { Age baseline (yr) } \\
\qquad p=0.126^{*}\end{array}$} & \multirow{2}{*}{$\begin{array}{l}\text { MS duration Baseline (month) } \\
\qquad p=0.381^{*}\end{array}$} \\
\hline & $\mathrm{M}$ & $\mathrm{F}$ & $\mathrm{C}$ & NC & & \\
\hline $\mathrm{R}(\mathrm{F})$ & $\begin{array}{c}n=14 \\
60.9 \%\end{array}$ & $\begin{array}{c}n=38 \\
55.9 \%\end{array}$ & $\begin{array}{c}n=40 \\
56.3 \%\end{array}$ & $\begin{array}{c}n=12 \\
60.0 \%\end{array}$ & $\begin{array}{c}n=52 \\
17-51 \text { years } \\
\text { Mean:31.6 yr }\end{array}$ & $\begin{array}{c}\mathrm{n}=52 \\
\text { 2.2-336.9 month } \\
\text { Mean: } 59.7 \mathrm{~m}\end{array}$ \\
\hline$N R(F)$ & $\begin{array}{c}n=9 \\
39.1 \%\end{array}$ & $\begin{array}{l}n=30 \\
44.1 \%\end{array}$ & $\begin{array}{l}n=31 \\
43.7 \%\end{array}$ & $\begin{array}{c}n=8 \\
40.0 \%\end{array}$ & $\begin{array}{c}n=39 \\
5-49 \text { years } \\
\text { Mean: } 28.4 \mathrm{yr}\end{array}$ & $\begin{array}{c}n=39 \\
\text { 1.2-256.6 month } \\
\text { Mean: } 68.5 \mathrm{~m}\end{array}$ \\
\hline
\end{tabular}

*p-value (Logistic Regression).

R: Responders; NR: nonresponders; GA: glatiramer acetate; C: Caucasian; NC: non-Caucasian; IFNb: interferon beta. (F): presence of any relapse confirmed at one year or an increase of at least one EDSS step confirmed at one year. 
Table 5. Treatment and MS duration. Percentage of responders.

\begin{tabular}{|c|c|c|c|c|}
\hline Treatment & Patients & $\begin{array}{c}\text { MS duration } \\
\text { baseline (month) }\end{array}$ & $\begin{array}{l}\text { MS duration baseline } \\
\text { mean (month) }\end{array}$ & $\begin{array}{c}\text { Percentage of } \\
\text { responders }\end{array}$ \\
\hline GA (Copaxone $\left.{ }^{\circledR}\right)$ & 22 & 5.27 to 152.17 & 48.4 & 59 \\
\hline IFNb-1a (Avonex $\left.{ }^{\circledR}\right)$ & 18 & 6.01 to 203.5 & 50.7 & 50 \\
\hline IFNb-1a-22 mg (Rebif $\left.{ }^{\oplus}\right)$ & 5 & 13.23 to 137.93 & 53.0 & 80 \\
\hline IFNb-1a-44 mg (Rebif $\left.{ }^{\circledR}\right)$ & 14 & 2.17 to 131.4 & 26.6 & 71 \\
\hline IFNb-1b (Betaferon $\left.{ }^{\circledR}\right)$ & 32 & 1.23 to 336.9 & 98.8 & 50 \\
\hline
\end{tabular}

MS: multiple sclerosis; IFNb: interferon beta; GA: glatiramer acetate.

As the immunomodulators consider as efficacy criteria the reduction of about $50 \%$ of annual relapse ratio, we compared the number of relapses one year prior the treatment. Considering as nonresponders patients who presented more than $50 \%$ of relapses comparing with the prior year, $36.2 \%$ of our patients were nonresponders. Río et al. ${ }^{10}$ found $20 \%$ of nonresponders. We can try to understand these differences if we analyze the interval of time disease until the treatment onset. The nonresponders patients of the present study were included in immunomodulatory treatment with a mean of 72.4 months considering only IFNb treatment (about 6.0 years of disease), and Río et al with a mean of 5.5 years of disease. The mean time of disease duration was not associated to a better response, but this result is probably associated with the low number of patients.

When we consider as nonresponders criteria both relapses and increased of at least one point in EDSS, we found here $43.5 \%$, the same result found for the relapse criteria, because all patients with increase of EDSS also presented new relapses. Río et al. ${ }^{10}$ found $49 \%$ of nonresponders regarding the same criteria and Fernández et al..$^{20}$ found 31.3\% among 96 MSRR Spanish patients, a similar number of patients studied in our sample. Although the differences among the three studies are not significant, Fernández et al. ${ }^{20}$ found a lower result even considering at least 0.5 point in the EDSS increased.

The validation of these parameters is important in order not to harm patients who had disease control, observed by an improvement in the period without treatment. Some predictors of poor response to IFNb have been suggested $^{10,15,24,25}$ in other studies, such as higher relapsing rate before the IFNb, older patients when starting ${ }^{15,18}$, longer duration of illness before starting IFNb ${ }^{15,18,24}$, or ethnicity $^{22}$. No differences here were found in demographic and clinical characteristics of patients that were similar to those reported in clinical trials of immunomodulators. No demographic factor was associated with a statistically significant response to treatment, regardless the definition of response $(\mathrm{p}>0.05)$.

Regarding the increase of EDSS and new relapses together as nonresponder criteria, the nonresponders presented a mean of 2.7 in EDSS and the responders, 2.6. The lack of difference in this parameter was not expected because the study of Fernández et al. and various recent studies have been showing that the better response to immunomodulatory treatment is associated to a lowest EDSS in the beginning ${ }^{20}$. Río et al. ${ }^{10}$ found similar results (with only IFNb treatment), EDSS 2.5 in nonresponders and 2.0 in responders.

All together, the proportion of non-responders patients ranged from 3.3 to $42.9 \%$ according to the definition used. These data points are consistent with those reported in the literature in which the observed proportion varies between 13 and $50 \%^{14,15,17,18,23-25}$.

The reasons for poor response to IFNb and GA are unclear, but may reflect the heterogeneity of MS and clinical phenotype depending of ethnic background. Regarding ethnicity, $43.7 \%$ Caucasians were nonresponders versus $40 \%$ non-Caucasians $(\mathrm{p}=0.615)$, a difference with no statistical significance.

Relapses and progression are the two basic clinical phenomena of MS. Relapses are considered to be the clinical expression of disseminated inflammation in the central nervous system, while the progression is considered to reflect the occurrence of demyelination, axonal loss and gliosis. In some patients, there is probably a predominance of demyelination and axonal degeneration in a progressive increase in disability, regardless of the presence of relapsing. The heterogeneity results found in the present study probably reflect characteristics of our population and need to be replicated in a larger sample, including MRI criteria and prospective data.

In conclusion, no statistical significant correlation was found among response or non-response according to gender, ethnicity, age at onset, EDSS at onset or duration of illness prior to starting immunomodulatory treatment.

\section{LIMITATIONS}

This study has several limitations. The number of patients with regular use during the first year was small, and the settings analyzed may not necessarily identify response to IFNb or GA, but groups of patients with different levels of activity and disease progression. However, this observation does not invalidate our results, as different definitions identify different types of response. 
1. Alves-Leon SV, Malfetano FR, Pimentel ML, Estrada CL, Pereira VC, Liem AM, et al. Multiple sclerosis outcome and morbi-mortality of a Brazilian cohort patients. Arq Neuropsiquiatr 2008;66:671-677.

2. Imitola J, Chitnis T, Khoury SJ. Insights into the molecular pathogenesis in the pathogenesis of progression in multiple sclerosis: potential implications for future therapies. Arch Neurol 2006;63:25-33.

3. Alves-Leon SV, Papais-Alvarenga R, Magalhães M, Alvarenga M, Thuler LCS, Fernández y Fernández O. Ethnicity-dependent association of HLA DRB1-DQA1-DQB1 alleles in Brazilian multiple sclerosis patients. Acta Neurol Scand 2007;115:306-311.

4. Cree BA, Khan O, Bourdette D, Goodin DS, Cohen JA, Marrie RA, et al. Comparison of the clinical characteristics of African American and Caucasian American patients with multiple sclerosis. Neurology 2004;63:2039-2045.

5. Kirstein-Grossman I,Beckmann JS, LancetD, MillerA.Pharmacogenetic Development of Personalized Medicine: Multiple Sclerosis Treatment as a Model. Drug News Perspect 2002;15:558-567.

6. $[10$ years of interferon treatment in multiple sclerosis. Does the future belong to high-dose therapy?] MMW Fortschr Med 2003;145:S108.

7. Academia Brasileira de Neurologia. Departamento Científico de Neuroimunologia. Guidelines for the treatment of multiple sclerosis with immunomodulatory drugs. Arq Neuropsiquiatr 2005;63:892-895.

8. Trojano M, Pellegrini F, Paolicelli D, Fuiani A, Zimatore GB, Tortorella $C$, et al. Real-life impact of early interferon beta therapy in relapsing multiple sclerosis. Ann Neurol 2009;66:513-520.

9. Polman $\mathrm{CH}$, Reingold SC, Banwell B, Clanet M, Cohen JA, Filippi M, et al. Diagnostic criteria for multiple sclerosis: 2010 revisions to the McDonald criteria. Ann Neurol 2011;69:292-302.

10. Río J, Nos C, Tintoré M, Téllez N, Galán I, Pelayo R, et al. Defining the response to interferon-b in relapsing-remitting multiple sclerosis patients. Ann Neurol 2006;59:344-352.

11. Mazdeh M, Afzali S, Jaafari MR. The therapeutic effect of Avonex, Rebif and Betaferon on EDSS and relapse in multiple sclerosis: a comparative study. Acta Med Iran 2010;48:83-88.

12. Poser CM, Paty DW, Scheinberg L, McDonald WI, Davis FA, Ebers GC, et al. New diagnostic criteria for multiple sclerosis: guidelines for research protocols. Ann Neurol 1983;13:227-231.
13. Lublin FD, Reingold SC. Defining the clinical course of multiple sclerosis: results of an international survey. National Multiple Sclerosis Society (USA) Advisory Committee on Clinical Trials of New Agents in Multiple Sclerosis. Neurology 1996;46:907-911.

14. Fusco C, Andreone V, Coppola G, Luongo V, Guerini F, Pace E, et al. HLA-DRB1*1501 and response to copolymer-1 therapy in relapsingremitting multiple sclerosis. Neurology 2001;57:1976-1979.

15. Waubant E, Vukusic S, Gignoux L, Dubief FD, Achiti I, Blanc S, et al. Clinical characteristics of responders to interferon therapy for relapsing MS. Neurology 2003;61:184-189.

16. Cohen BA, Khan O, Jeffery DR, et al. Identifying and treating patients with suboptimal responses. Neurology 2004;63:S33-S40.

17. Rudick R, Lee J, Simon J, Ransohoff RM, Fisher E. Defining interferon response status in multiple sclerosis patients. Ann Neurol 2004;56:548-555.

18. Villoslada P, Oksenberg JR, Rio J, Montalban X. Clinical characteristics of responders to interferon therapy for relapsing MS. Neurology 2004;62:1653.

19. Baranzini SE, Mousavi P, Rio J, Caillier SJ, Stillman A, Villoslada P, et al. Transcription-based prediction of response to IFNbeta using supervised computational methods. PLoS Biol 2005;3:e2

20. Fernandez-Fernandez O, Fernandez-Sanchez VE, Mayorga C, Guerrero-Fernandez M, Leon A, Tamayo-Toledo JA, et al. Interferonbeta response in multiple sclerosis associated with pre-treatment disability. Rev Neurol Spain 2006;43:322-329.

21. Lublin FD. Clinical features and diagnosis of multiple sclerosis. Neurol Clin 2005;23:1-15.

22. Cree BAC,Al-Sabbagh A, Bennett R, Goodin D. Response to interferon beta-1a treatment in African American multiple sclerosis patients. Arch Neurol 2005;62:1681-1683.

23. Río J, Nos C, Tintoré M, Téllez N, Galán I, Pelayo R, et al. Assessment of different treatment failure criteria in a cohort of relapsingremitting multiple sclerosis patients treated with interferon beta: implications for clinical trials. Ann Neurol 2002;52:400-406.

24. Kappos L, Polman C, Pozzilli C, Thompson A, Beckmann K, Dahlke F, et al. Final analysis of the European multicenter trial on IFNb-1 b in secondary progressive MS. Neurology 2001;57:1969-1975.

25. KrackeA, von Wussow P,Al-MasriA, Dalley G, Windhagen A, Heidenreich F. Mx proteins in blood leukocytes for monitoring interferon beta- $1 \mathrm{~b}$ therapy in patients with MS. Neurology 2000;54:193-199. 